\title{
Increasing bowel cancer screening
}

\section{participation: integrating population-wide,} primary care and more targeted approaches

\author{
Kerryann L Lotfi-Jamª, ${ }^{a, c}$ Clare L O'Reilly ${ }^{\mathrm{b}}$, Charissa S Feng ${ }^{\mathrm{b}}$, \\ Melanie A Wakefield ${ }^{a}$, Sarah Durkina and Kate H Broun ${ }^{b}$ \\ a Centre for Behavioural Research in Cancer, Cancer Council Victoria, Melbourne, Australia \\ b Prevention Division, Cancer Council Victoria, Melbourne, Australia \\ c Corresponding author: Kerryann.Lotfi-Jam@cancervic.org.au
}

\section{Article history}

Publication date: July 2019

Citation: Lotfi-Jam KL, O'Reilly CL, Feng CS, Wakefield MA, Durkin S, Broun KH. Increasing bowel cancer screening participation: integrating population-wide, primary care and more targeted approaches. Public Health Res Pract. 2019;29(2):2921916. https://doi.org/10.17061/phrp2921916

\section{Key points}

- The Australian National Bowel Cancer Screening Program (NBCSP) provides free screening to eligible people aged 50-74 years

- NBCSP participation is suboptimal, particularly among Aboriginal and Torres Strait Islander people, some culturally and linguistically diverse communities, and other groups experiencing social disadvantage

- Mass media campaigns, targeted awareness and education programs, and primary care strategies may increase NBCSP participation

- Tailored strategies are required to support participation by underscreened populations

- General practitioner endorsement is one of the strongest motivational factors to participate in screening

\section{Abstract}

Objectives: Participation in the Australian National Bowel Cancer Screening Program (NBCSP) is suboptimal. Given the program's enormous potential to save lives, Cancer Council Victoria has prioritised increased screening participation as part of its strategic plan. This paper describes the implementation, and evaluation where available, of Cancer Council Victoria programs to increase participation, supported by a mix of own organisation and Victorian state health department funding.

Type of programs: At the population level, Cancer Council Victoria has delivered television-led mass media campaigns to motivate age-eligible individuals to complete and return their NBCSP kit. It has also delivered targeted awareness and education programs for underscreened populations including Aboriginal and Torres Strait Islander people, people from culturally and linguistically diverse communities, and groups experiencing social disadvantage. Programs involving general practice have also been trialled to improve the knowledge and confidence of general practitioners (GPs) to discuss bowel screening with their patients, and to implement identification, reminder and follow-up systems to improve bowel screening participation.

Results: There is strong evidence to support the use of mass media public health campaigns, which have resulted in significant increases in screening kit return rates. Targeted education sessions with underscreened communities have led to increases in knowledge about bowel cancer screening, confidence to do the test and intention to participate in the NBCSP in communities where these sessions have been trialled. Early findings suggest that GP endorsement strategies are welcomed by patients and are an effective way to encourage NBCSP participation. System changes using patient information systems may be more challenging, given the inconsistent entry of NBCSP data.

Lessons learnt: Our work to date demonstrates that there is a strong case for regular, widespread mass media strategies to increase NBCSP participation. There is also evidence to support more tailored, complementary approaches with dedicated education programs for underscreened groups, and active and sustained engagement with underscreened communities and primary care providers to overcome personal, cultural and systems barriers to screening. Improved data capture capabilities are needed to better implement and evaluate the impact of future strategies to improve NBCSP participation. 


\section{Introduction}

Bowel cancer is the second most common cause of cancer-related death in Australia. ${ }^{1}$ However, if detected at stage I, almost $99 \%$ of those diagnosed survive 5 years or more. ${ }^{1}$ Detection and removal of precancerous adenomatous polyps through screening prevents a cancer diagnosis altogether. Noninvasive screening tests including the immunochemical faecal occult blood test (iFOBT) can detect bowel cancer and its precancerous conditions in the early stages, increasing the likelihood of successful treatment.

The National Bowel Cancer Screening Program (NBCSP) was introduced in Australia in 2006, involving the mail-out of free iFOBT kits to people aged 5074 years. The program has been slowly phased in since that time, with different age groups within the target population added, initially in 5-yearly then 2-yearly intervals. Full implementation based on biennial invitations to all average-risk Australians aged 50-74 will be complete by 2020 . The roll-out has met challenges ${ }^{2-4}$ including: limited public and health professional understanding of how and when to access the program while age groups were added; limited GP consultation in the development of the program; long waiting lists for colonoscopies for positive screening tests; lack of ready access to screening tests to enable those motivated by messages to act on them; and inequity in access due to reliance on mail services to distribute and return iFOBT kits. These factors are thought to have led, in part, to limited promotion of the program and suboptimal national participation rates. Currently $41 \%$ of those invited participate in screening ${ }^{1}$, and the rate is much lower among those aged 50-55, Aboriginal and Torres Strait Islander peoples (hereafter referred to as Indigenous people), people from some culturally and linguistically diverse communities (hereafter referred to as culturally diverse communities), people with disabilities, and groups experiencing social disadvantage. These groups are referred to as underscreened populations.

Recognising the enormous potential for the NBCSP to save lives, Cancer Council Victoria prioritised screening participation in its 2017-2021 Strategic Plan. ${ }^{5}$ The aim of this paper is to: 1) review known barriers to screening participation and evidence for interventions to increase screening uptake; 2) summarise Cancer Council Victoria's recent programs, evaluation efforts and early results where known; and 3) provide guidance on future program development, applying the lessons learnt and challenges faced to date. This paper focuses on increasing participation in the NBCSP specifically as recommended in the National Health and Medical Research Council guidelines ${ }^{6}$, rather than the use of commercially available bowel screening kits.

\section{Barriers to bowel cancer screening participation}

Recent Australian studies have found low levels of public awareness of the burden of bowel cancer, compared with other more high profile cancers. ${ }^{4}$ Earlier population-based surveys also showed that older people in particular believed that screening was only necessary if they experienced symptoms. ${ }^{6}$ This low perception of risk represents a major barrier to participation, and has led to a tendency for people to 'forget about' or 'not get around to doing' the kit when invited. ${ }^{4}$ For those from non-English speaking and disadvantaged backgrounds, other significant barriers include: language difficulties; limited promotion of the program in community languages; complex, difficultto-understand test kit instructions; limited access to primary healthcare; and lack of endorsement by general practitioners (GPs). ${ }^{7-10}$ Additionally, differing cultural beliefs around a cancer diagnosis including fear, stigma and shame may thwart participation. ${ }^{4,8}$ Public education, tailored support and strategies that promote access to the NBCSP are therefore required to increase screening participation.

Primary care providers can play a critical role in encouraging participation, but gaps in GP knowledge of the NBCSP and low confidence to discuss cancer screening with patients may also contribute to poor participation. ${ }^{11}$ Interview findings from a qualitative study in New South Wales (NSW), Australia, which examined GP perceptions of screening indicated that many questioned the efficacy of the iFOBT, particularly compared with colonoscopy, and continued to refer patients directly to colonoscopy, despite their low risk of bowel cancer. ${ }^{12}$ Furthermore, significant systems barriers include limited capacity for discussion in the busy primary care setting; challenges with identifying patients who are overdue for screening because it is done outside of the practice setting; and difficulties following up with such patients because of inconsistencies in the way in which results are entered into patient health records. ${ }^{12,13}$ Strategies are urgently needed to overcome these barriers, to enable primary care providers to promote NBCSP participation.

\section{Strategies to improve NBCSP participation}

Because of the program's infancy and the very modest investment in promoting participation to date, little has been published on the effectiveness of screening promotion strategies. Evidence is, however, available on the promotion of cervical and breast screening programs, which have been fully implemented in Australia since 1991 and 1995, respectively. Screening interventions can be broadly categorised into the following areas: 1) mass media public health campaigns; 2) targeted education and support programs; and 3) primary care engagement and health systems improvements. Cancer Council Victoria has commenced work in each of these areas, which will be summarised in the following sections. 


\section{Mass media campaigns}

Awareness and understanding are the critical first steps to changing health behaviour ${ }^{14}$, so broad promotion of the NBCSP to encourage participation in bowel screening is vital. Mass reach multimedia campaigns can promote the importance of, and urgency for, using the at-home iFOBT test, with television-led campaigns complemented by other traditional and digital media shown to reach a high proportion of older adults. ${ }^{15}$ An evaluation of a 2014 Cancer Council Australia-led NBCSP media campaign showed a significant $20 \%$ increase in the rate of iFOBT kits returned for analysis during and up to 2 months after the campaign was run in Queensland, compared with the baseline rate of return observed in the previous 2.5 years. In Western Australia (WA), residents were not exposed to the televised 30-second advertisement and only received exposure to the supportive campaign elements which included print advertisements, 4-minute television advertorials, and digital and online advertising. An $11 \%$ increase in the rate of returns above the baseline return rates in WA was observed but was not statistically significant. ${ }^{16}$

Based on these findings, Cancer Council Victoria funded the television-led campaign to be re-run in Victoria in 2017, and compared responses with those from South Australia, where no campaign aired but a limited number of nationally syndicated daytime television advertorials were broadcast. A representative pre-post population survey of 1700 individuals aged $50-74$ years found that $80 \%$ of Victorians and $24 \%$ of South Australians were aware of at least one campaign element, and $40 \%$ of those exposed discussed the message with someone else. Among Victorians who were aware of the campaign, a large majority found it believable $(97 \%)$ and relevant (87\%), and reported feeling greater perceived control over their future health (87\%); $69 \%$ reported the campaign made them think about how their family and friends would feel if they got bowel cancer. ${ }^{17}$ In addition, Victorians showed a significant increase in the rate of iFOBT kit returns during and soon after the campaign aired compared with baseline return rates, and these increases were significantly greater than among South Australians. Each of these increases in kit return rates were reflected equally across NBCSP-eligible age groups, gender and socio-economic groups. ${ }^{18}$ Importantly, the increased rate of campaign-associated participation was greater among first-time screeners than repeat screeners. This is a key outcome because once an individual has undertaken screening for the first time, they are nearly three times more likely to screen again compared with a first-time invitee. ${ }^{1}$

These encouraging population-wide findings make a strong case for the national funding of regular mass reach media campaigns to continue to prompt age-eligible adults to participate in the NBCSP.

\section{Targeted interventions to identify under- screened populations}

\section{Although population-wide health messaging has} demonstrated success, cultural and language barriers may result in broad campaigns being less likely to reach, or be as effective, in some groups. Recognising this, the Victorian Department of Health and Human Services funded Cancer Council Victoria to identify key underscreened population groups and subgroupspecific barriers. Currently it is not possible to determine specific participation rates for population groups, as sociodemographic information is not available for NBCSP invitees, and is only recorded for those participants who choose to self-identify on the form when they return their kit. However, population data from the Australian Bureau of Statistics was used to estimate the number of invitations sent to different population groups and to calculate estimated participation rates using the known participant information. ${ }^{1}$ This method identified several groups with low participation rates. Extensive consultation with these underscreened communities, including Indigenous and several culturally diverse communities, revealed significant gaps in information and access to the NBCSP for those who do not speak English or who have additional support needs. ${ }^{1,19}$ Suggestions that participation could be increased by the use of plain language instructions, in-language education and endorsement by GPs ${ }^{10}$ were prioritised, with newly developed and translated information resources and kit instructions made available in several languages and disseminated within appropriate communities..$^{20}$

Cancer Council Victoria also implemented several local initiatives to complement the mainstream mass media campaign. For example, community-led bowel screening education sessions were delivered to approximately 480 people from Greek, Italian, Sri Lankan and Indian communities in 2018. Sessions were led by individuals from the same community as the target audience, trained to provide education, emotional and logistical support and advice, as recommended in a recent systematic review of interventions to increase screening in underscreened populations. ${ }^{21}$ Each session offered information about bowel cancer and the importance of regular screening, advice and practical instructions on how to undertake the test, and opportunities to ask questions. Pre-post evaluation results showed that $72 \%$ of participants reported a good or very good understanding of bowel cancer screening after the session, compared to just $40 \%$ before the session. ${ }^{12}$ Eighty-two per cent of attendees reported that the session had increased their confidence to complete the kit, and $75 \%$ reported that they intended to participate when their NBCSP kit next arrived. ${ }^{13}$ Although there is room for improvement, and the impact on participation is not yet known, tailored in-language, or culturally appropriate, education delivered in community settings appears to be a valuable strategy to deliver screening information. 
Cancer Council Victoria has also established effective partnerships with self-advocacy organisations and developed innovative strategies to meet the needs of different groups. For example, in response to Indigenous community recommendations that humour is an effective health communication strategy, a comedy show about bowel cancer screening was developed in collaboration with Denise McGuinness, an Aboriginal comedian, and delivered to several Indigenous audiences around Victoria. The comedy show, which promoted key bowel screening messages and the NBCSP, was very well received. A sample of 43 attendees completed evaluation surveys before and after the show, with $76 \%$ reporting they had a good or very good understanding of bowel screening after the show, compared with $30 \%$ prior. Further, $96 \%$ of those surveyed after the show reported they were confident to use the test, and $88 \%$ of those eligible intended to screen within the next 12 months. ${ }^{13}$ Despite the small sample, the show provides a promising example of how health information can be delivered through nontraditional mechanisms in order to be more acceptable to hard-to-reach community groups.

\section{The value of primary care engagement}

General practice and community health centres are uniquely placed to provide information, resources and encouragement to patients. During the 2017 mass media campaign, advertising and printed resources were provided in general practice waiting rooms. A population survey found that $45 \%$ of those who recalled or recognised the campaign identified this as an information source. ${ }^{17}$

To address barriers in GP knowledge and confidence, several initiatives have been trialled to educate GPS about optimal bowel cancer screening and the NBCSP. An educational GP workshop that was attended by 38 GPs and viewed via webinar by a further 65 GPs resulted in $60 \%$ of participants reporting they had a 'very good' or 'excellent knowledge' of the NBCSP, compared to just $24 \%$ before the session. ${ }^{11}$ Although this increase after a single session is promising, additional support is required. To further improve on this, Cancer Council Victoria recently partnered with the Department of General Practice at the University of Melbourne to develop a program to deliver bowel screening education, tailored recommendations and a GP toolkit to 120 general practices in Victoria. This more extensive support for general practice aims to increase GP knowledge and confidence to deliver bowel screening advice and to implement practice systems improvements over a 6-month period after the initial session.

Studies consistently show that GP endorsement is one of the strongest motivational factors for people to participate in cancer screening. ${ }^{22}$ Routine discussion with patients aged 50-74 years, showing patients how to use the NBCSP kit, and implementing systems to identify underscreened patients and send endorsed reminder letters or SMSs may also help to increase screening rates. ${ }^{22}$ Cancer Council Victoria recently pilot-tested the mail-out of an endorsement letter from a general practice to all patients aged 50-74 years, including a large proportion who were from South Asian backgrounds. Preliminary findings from interviews with a sample of 50 patients found that more than $80 \%$ reported that the letter helped them to understand why bowel cancer screening was important and helped them to decide whether or not to do the test.13 GP endorsement strategies such as this have strong potential to motivate patients to participate in screening. However, the scalability and economic viability of such campaigns is limited by the inability to systematically identify the target group (in this case South Asian people aged 50-74 years who had not participated in bowel cancer screening in the past 2 years). NBCSP data and results are not consistently uploaded into patient electronic health records in a format that is searchable, and this is an area which requires further consideration.

\section{Recommendations for future campaigns}

Despite the early stage of some of the work presented, the evidence shows there is an increasingly strong case for recurrent funding for mass media public health campaigns to improve bowel screening participation. It is worth noting that in January 2019, the Australian Government announced \$10 million in funding for an "advertising blitz" to encourage more people to participate in the NBCSP. ${ }^{23}$ A national multimedia campaign is currently underway.

Targeting underscreened groups at the community level and through the primary health care system can also ensure equitable access and opportunity to participate in NBCSP by those who may otherwise be missed by mainstream campaigns.

With consideration for the challenges we have faced, our key recommendations to guide future efforts to increase NBCSP participation are:

1. Television-led mass media campaigns complemented by other media are highly effective in immediately improving participation rates in the population, especially among first- time screeners. However, campaigns need regular repetition and message refreshment to cue timely kit completion, because age-eligible people receive invitations to participate in the NBCSP throughout the entire year.

2. Dedicated, tangible engagement is needed to understand the unique needs and priorities of underscreened communities. A partnership approach with community-led organisations can assist with engagement of hard-to-reach groups, including codesign of programs and evaluation when appropriate. Rapport building takes time, compromising short-term projects; therefore a longerterm strategy that builds in adequate and sustained community consultation to develop strength-based strategies is required. 
3. It can be difficult to measure improvements resulting from community-based programs, particularly when language is a barrier. The impact of communityfocused promotional activities on awareness and screening behaviours can also be difficult to quantify. ${ }^{24}$ Innovative and flexible methods need to be considered when delivering and evaluating such programs.

4. Although primary care is key to increasing participation in screening, there are ongoing challenges in engaging GPs in educational and capacity-building activities. GPs are often reluctant or unable to attend face-to-face sessions, and systemsbased strategies to encourage participation in screening can be delayed or forgotten in busy clinics without additional staff or time allocated. ${ }^{25}$

\section{Conclusion}

The mortality, morbidity and cost-saving benefits of bowel cancer screening are extraordinary and increase in step with program participation rates. Cancer Council Victoria, in partnership with the Victorian Department of Health and Human Services and the Cancer Council federation, has made significant efforts to increase NBCSP participation. Promising strategies have been trialled, which could be implemented at scale. Initiatives should focus on delivery of television-led mass media campaigns targeted at the population of age-eligible individuals, ongoing consultation with underscreened communities to provide education and support that is tailored to their varied needs, engaging with primary care providers to provide evidence based information and support, and introducing systems-based improvements that will allow screening strategies to be more easily implemented and evaluated.

\section{Acknowledgements}

Grants from the Victorian Government Department of Health and Human Services and the South East Melbourne Primary Health Network were used to fund several activities described in this paper.

\section{Peer review and provenance}

Externally peer reviewed, commissioned.

\section{Competing interests}

None declared.

\section{Author contributions}

$\mathrm{KL}, \mathrm{CO}, \mathrm{CF}$ and $\mathrm{KB}$ designed the paper; $\mathrm{KL}, \mathrm{CO}, \mathrm{CF}$, $\mathrm{KB}$ and $\mathrm{MW}$ drafted it, $\mathrm{KL}$ and $\mathrm{SD}$ analysed the data, all authors were involved in editing and reviewing the paper

\section{References}

1. Australian Institute of Health and Welfare. National Bowel Cancer Screening Program: monitoring report 2019. AlHW: Canberra, 2019 [cited 2019 Jun 19]. Available from: www.aihw.gov.au/getmedia/840c72ff-a0e6-40cb9b42-f68bfae112d2/aihw-can-125.pdf.aspx?inline=true

2. Dawson G, Crane M, Lyons C, Burnham A, Bowman T, Travaglia J. A qualitative investigation of factors influencing participation in bowel screening in New South Wales. Health Promot J Austr. 2016;27(1):48-53.

3. Varlow M, Stacey I, Dunlop S, Young J, Kite J, Dessaix A, et al. Self-reported participation and beliefs about bowel cancer screening in New South Wales, Australia. Health Promot J Austr. 2014;25(2):97-103.

4. Scalzo K. Bowel cancer screening: results from an online survey of Victorians. Victoria; Cancer Council Victoria;2015; Available on request from: Cancer Council Victoria.

5. Cancer Council Victoria. Strategic plan 2017-2021. Melbourne: Cancer Council Victoria; 2017 [cited 2019 Jun 19]. Available from: www.cancervic.org.au/about/ strategic-plan

6. Cancer Council Australia Colorectal Cancer Guidelines Working Party. Clinical practice guidelines for the prevention, early detection and management of colorectal cancer. Sydney: Cancer Council Australia; 2018 [cited 2019 Apr 1]. Available from: wiki.cancer.org.au/ australiawiki/index.php?oldid=191477

7. Phillipson L, Hall J, Pitts L, Hunt T. Project Good News - engaging priority CALD communities to reduce the stigma associated with cancer. Second Annual Innovations in Cancer Services and Care Conference. Wollongong: University of Wollongong Research Online; 2013 [cited 2019 Jun 18]. Available from: ro.uow.edu.au/ cgi/viewcontent.cgi?referer $=\&$ httpsredir $=1 \&$ article $=1342$ \&context=sspapers

8. Phillipson L, Larsen-Truong K, Jones S, Pitts L. Improving cancer outcomes among culturally and linguistically diverse communities: a rapid review of the literature. Wollongong: University of Wollongong Research Online; 2012 [cited 2019 Jun 18]. Available from: ro.uow.edu.au/ cgi/viewcontent.cgi?article $=1485 \&$ context=sspapers

9. Cullerton K, Gallegos D, Ashley E, Do H, Voloschenko A, Fleming $\mathrm{M}$, et al. Cancer screening education: can it change knowledge and attitudes among culturally and linguistically diverse communities in Queensland, Australia? Health Promot J Austr. 2016;27(2):140-47.

10. Phillipson L, Pitts L, Hall J, Tubaro T. Factors contributing to low readiness and capacity of culturally diverse participants to use the Australian national bowel screening kit. Public Health Res Prac. 2019;29(1):e28231810. 
11. Lotfi-Jam K. Improving cancer screening in the community: a co-designed program between Cancer Council Victoria and SEMPHN. Evaluation of activities: July 2017 - April 2018. Melbourne: Cancer Council Victoria; 2018. Available on request from: Cancer Council Victoria.

12. Dawson G, Crane M, Lyons C, Burnham A, Bowman T, Perez D, et al. General practitioners' perceptions of population based bowel screening and their influence on practice: a qualitative study. BMC Fam Pract. 2017;18(1):36.

13. Lotfi-Jam K. 2018 Priority communities bowel campaign evaluation. Cancer Council Victoria. Forthcoming 2019. Copy available from authors.

14. Rimer BK. Theory at a glance: a guide for health promotion practice (Second Edition), K Glanz, editor. US Department of Health and Human Services. National Institutes of Health, National Cancer Institute: Bethesda, MD; 2005 [cited 2019 Jun 18]. Available from: www. sbccimplementationkits.org/demandrmnch/wp-content/ uploads/2014/02/Theory-at-a-Glance-A-Guide-For-HealthPromotion-Practice.pdf

15. Durkin S, Wakefield M. Media use and trends and implications for potential reach of public education and motivation campaigns: application to tobacco control. Melbourne: Cancer Council Victoria; 2018 [cited 2019 Jun 19]. Available from: www.cancervic.org.au/ downloads/cbrc_research_papers/CBRC_RPS_No.49.pdf

16. Durkin S, Broun K, Spittal M, Wakefield M. Impact of a mass media campaign on participation rates in a national bowel cancer screening program: a field experiment. BMJ Open. 2019;9:e024267.

17. Morley B, Durkin S and Wakefield M. Evaluation of Cancer Council Victoria's 2017 bowel screening campaign. Melbourne: Cancer Council Victoria; 2018 [cited 2019 Jun 18]. Available from: www.cancervic.org. au/downloads/cbrc/Bowel_Screen_campaign 2017_eval rpt_20190530.pdf
18. Durkin S, Broun K, Guerin N, Morley B, Wakefield M. Mass media campaign impact on overall and subgroup participation rates in the Australian national bowel cancer screening program: a field experiment. Forthcoming 2019. Copy available from authors.

19. Scalzo K. Bowel cancer messages for Aboriginal communities in Victoria: report of qualitative research. Melbourne: Cancer Council Victoria; 2014. Available on request from: Cancer Council Victoria.

20. Cancer Council Victoria. Finding bowel cancer early can save your life. Melbourne: Cancer Council Victoria; 2019 [cited 2019 Jun 19]. Available from: www.cancervic.org. au/downloads/cpc/bowel/bowel-fobt-instruction-brochure. pdf (translations available from Cancer Council Victoria).

21. Rees I, Jones D, Chen H, Macleod U. Interventions to improve the uptake of cervical cancer screening among lower socioeconomic groups: a systematic review. Prev Med. 2018;111:323-35.

22. Duffy SW, Myles JP, Maroni R, Mohammad A. Rapid review of evaluation of interventions to improve participation in cancer screening services. J Med Screen. 2017;24(3):127-45.

23. Australian Government Ministers, Department of Health. $\$ 10$ million to boost bowel cancer screening participation. Canberra: Commonwealth of Australia; 2019 [cited 2019 Jun 18]. Available from: beta.health.gov.au/ministers/thehon-greg-hunt-mp/media/10-million-to-boost-bowelcancer-screening-participation

24. Martini A, Morris JN, Preen D. Impact of non-clinical community-based promotional campaigns on bowel cancer screening engagement: An integrative literature review. Patient Educ Couns. 2016;99(10):1549-57.

25. Cancer Council Victoria. Under screened recruitment program: year three evaluation report. Melbourne: Cancer Council Victoria; 2017. Available on request from: Cancer Council Victoria.

\section{Copyright: (c) (i) (2)}

(C) 2019 Lotfi-Jam et al. This article is licensed under the Creative Commons Attribution-NonCommercial-ShareAlike 4.0 International Licence, which allows others to redistribute, adapt and share this work non-commercially provided they attribute the work and any adapted version of it is distributed under the same Creative Commons licence terms. See: www.creativecommons.org/licenses/by-nc-sa/4.0/ 